\title{
Calcium ions promote primary renal epithelial cell differentiation into cells with bone-associated phenotypes via transforming growth factor- $\beta 1$-induced epithelial-mesenchymal transition in idiopathic hypercalciuria patients
}

\author{
DENG HE, SHAOGANG WANG, ZHAOHUI JIA, LEI CUI, YUCHAO LU, HENGLONG HU and BAOLONG QIN
}

\begin{abstract}
Department of Urology, Tongji Hospital, Tongji Medical College, Huazhong University of Science and Technology, Wuhan, Hubei 430030, P.R. China
\end{abstract}

Received March 1, 2014; Accepted October 31, 2014

DOI: $10.3892 / \mathrm{mmr} .2014 .2941$

\begin{abstract}
The present study aimed to identify the characteristics and cross-talk between transforming growth factor $\beta 1$ (TGF- $\beta 1$ ) and calcium ions in nephrolithiasis patients with idiopathic hypercalciuria $(\mathrm{IH})$ in order to elucidate the potential mechanisms underlying changes in cell phenotype induced by bone-associated factors and their influence on renal nephrolithiasis formation. Blood samples from a total of 29 nephrolithiasis patients with IH, 29 renal stone patients without IH and 29 healthy age-matched normal controls were subjected to quantification of peripheral serum TGF- $\beta 1$, osteopontin (OPN) and bone morphogenetic protein 2 (BMP2) using ELISA. This was followed by detection of BMP2, OPN and 1,25-dihydroxyvitamin $\mathrm{D}_{3}$ receptor (VDR) mRNA and protein levels in primary renal epithelial cells (PRECs) of IH and HK-2 human proximal tubular cell lines (control) using reverse transcription quantitative polymerase chain reaction (RT-qPCR) and western blot analyses. The mRNA expression levels of BMP2, OPN and VDR in PRECs and HK-2 were evaluated following stimulation with various concentrations of TGF- $\beta 1(0.5,2.0$ and $5.0 \mathrm{ng} / \mathrm{ml}), \mathrm{Ca}^{2+}(0.5,1.5$ and $2.5 \mathrm{mM})$ or TGF- $\beta 1$ and $\mathrm{Ca}^{2+}$ combined using RT-qPCR, respectively. TGF- $\beta 1$, BMP2 and OPN expression levels in patients with IH were all significantly higher than those in the control group. The mRNA and protein expression levels of BMP2 and VDR were significantly higher in PRECs than those in HK-2 cells. Following incubation with TGF- $\beta 1$ and/or $\mathrm{Ca}^{2+}$, the mRNA expression levels of BMP2, OPN and VDR in PRECs increased in a dose-dependent manner; however,
\end{abstract}

Correspondence to: Professor Shaogang Wang, Department of Urology, Tongji Hospital, Tongji Medical College, Huazhong University of Science and Technology, 1095 Jiefang Avenue, Wuhan, Hubei 430030, P.R. China

E-mail: sgwangtjm@163.com

Key words: transforming growth factor $\beta 1$, idiopathic hypercalciuria, renal tubular epithelial cell no significant differences were observed in HK-2 cells with increasing TGF- $\beta 1$ dosage. Co-incubation with TGF- $\beta 1$ and $\mathrm{Ca}^{2+}$ in PRECs and HK-2 cell lines resulted in similar effects and the expression of BMP2, OPN and VDR mRNA increased in a time-dependent manner. In conclusion, the results of the present study demonstrated that TGF- $\beta 1$ regulated the expression of BMP2, OPN and VDR in PRECs, but not in HK-2 cells. Co-incubation with TGF- $\beta 1$ and $\mathrm{Ca}^{2+}$ significantly increased the expression levels of bone-associated factors in PRECs and HK-2 cells, which suggested that this process may be partially responsible for the pathogenesis of calcium stone development, and also associated with bone formation and the TGF- $\beta 1$-induced epithelial to mesenchymal transition.

\section{Introduction}

Nephrolithiasis is associated with multiple metabolic abnormalities and is one of the most prevalent diseases with uncertain etiology amongst adults (1). Idiopathic hypercalciuria (IH) is the most common metabolic disorder to occur in adult calcium stone formers, present in $\sim 30-60 \%$ of such patients, and is also common among pediatric calcium stone formers (2). The development of IH is influenced by genetic background and environment (2). Previous studies have demonstrated that hypercalciuria may involve the dysregulation of multiple calcium transport systems, including increased intestinal absorption of calcium, primary renal calcium leakage and increased bone demineralization $(3,4)$. Despite extensive study, the molecular and genetic causes of stone diseases have remained elusive.

Members of the transforming growth factor $\beta$ (TGF- $\beta$ ) family participate in numerous physiological and pathological processes, have vital roles in biological processes, including cell differentiation, proliferation and apoptosis, and regulate the growth, development and regeneration of extracellular materials (5). The function of the profibrotic cytokine TGF- $\beta 1$ in the initiation and progression of fibrosis in the kidney has been extensively studied and certain studies have indicated that TGF- $\beta 1$ may have an important function in mediating the epithelial to mesenchymal transition (EMT), where renal tubular epithelial cells lose their epithelial phenotype and a 
novel mesenchymal phenotype is obtained following treatment with TGF- $\beta 1(6,7)$. Furthermore, studies have revealed that $\mathrm{Ca}^{2+}$ is a potent, suppressive effector that induces undifferentiated mesenchymal stem cells (MSCs) to differentiate into numerous cell types via intracellular $\mathrm{Ca}^{2+}$ release (8). However, to date, the specific effects of TGF- $\beta 1$ and $\mathrm{Ca}^{2+}$ in IH, as well as in renal stone formation, have remained to be elucidated.

In the present study, the expression of bone morphogenetic protein 2 (BMP2), osteopontin (OPN) and 1,25-dihydroxyvitamin $D_{3}$ receptor (VDR) were evaluated in nephrolithiasis patients with IH, compared with renal stone patients without IH and healthy age-matched normal controls. These factors are closely associated with osteoblastic differentiation and bone formation. The results of the present study indicated that TGF- $\beta 1$ and $\mathrm{Ca}^{2+}$ may regulate the expression of bone-associated factors, including BMP2, OPN and VDR, in renal tubular epithelial cells in IH to further promote calculus formation in situ. Taken together, it was hypothesized that TGF- $\beta 1$-induced EMT and $\mathrm{Ca}^{2+}$-induced mesenchymal osteogenetic differentiation were involved in nephrolithiasis in $\mathrm{IH}$.

\section{Materials and methods}

Patients. In the present study, 29 nephrolithiasis patients with idiopathic hypercalciuria (mean \pm standard deviation; age, $32.1 \pm 9.5$ years; range, 20-57 years) were recruited as group $\mathrm{IH}$ and 29 healthy age-matched volunteers $(30.5 \pm 10.6$ years; range, 22-54 years) were recruited as normal controls (NC group). Furthermore, 29 renal stone patients without idiopathic hypercalciuria (35.6 \pm 12.1 years; range, $21-58$ years) were recruited as the nIH group. IH was diagnosed by $24-\mathrm{h}$ urine $\mathrm{Ca}^{2+}$ excretion rates $>140 \mathrm{mg} \mathrm{Ca}^{2+} / \mathrm{g}$ urine creatinine on outpatients without dietary restrictions (9). Patients with systemic $\mathrm{Ca}^{2+}$ disorders, including hyperthyroidism and diabetic nephropathy, were excluded. All procedures were approved by the Ethical Committee of Tongji Hospital of Tongji Medical College, Huazhong University of Science and Technology (Wuhan, China). Prior to participation in the study, informed consent was obtained from all subjects.

Measurement of TGF- $\beta 1$, BMP2 and OPN by ELISA. Blood samples $(5 \mathrm{ml})$ were drawn from patients in the $\mathrm{IH}, \mathrm{NC}$ and $\mathrm{nIH}$ groups. Following centrifugation at 20,000xg for $15 \mathrm{~min}$, sera were collected and aliquoted into 96-well plates (100 $\mu \mathrm{l} /$ well). The expression levels of TGF- $\beta 1$, BMP2 and OPN were detected using corresponding TGF- $\beta 1$-, BMP2and OPN-specific human ELISA kits (R\&D Systems, Inc., Minneapolis, MN, USA). Sera samples were acidified with $1 \mathrm{~mol} / 1 \mathrm{HCl}$ solution to activate the cytokines to their immunoreactive states ( $\mathrm{pH} 2.0-3.0)$, prior to neutralization according to the manufacturer's instructions and the addition of $50 \mu \mathrm{l}$ diluent RD-121 to each well. Subsequently, a $50 \mu 1$ sample from each group was added in triplicate to each well for $2 \mathrm{~h}$. Following washing three times with phosphate-buffered saline (PBS; pH 7.2) containing 0.05\% Tween 20 (Sigma-Aldrich), substrate solution was added to each well for 30 min until the reaction was stopped by the additon of Stop Solution. Optical density was measured at $450 \mathrm{~nm}$ using microplate reader SPR-960 (Sunostik Medical Technology Co., Ltd, Changchun, China) and cytokine levels were calculated by standard curves.
Preparation of primary renal epithelial cells (PRECs) from patients with $I H$. All patients with $\mathrm{IH}$ received invasive surgical treatment for urolithiasis. Two patients were required to receive a nephrectomy due to ipsilateral renal severe hydronephrosis and renal failure, according to diagnosis by computed creatinine and emission tomography tests. A section of renal tissue was removed from each subject under sterile conditions. Isolation and culture of human renal epithelial cells was performed as described by a previous study (10). Briefly, cortical tissue was finely minced, washed multiple times and agitated for $20 \mathrm{~min}$ at $37^{\circ} \mathrm{C}$ in Hanks' balanced salt solution (HBSS) containing collagenase type II and calcium (Merck Co., Shanghai, China). HBSS was added and the solution containing tubular fragments was passed through a 100- $\mu$ m sieve (LFJ706; EHSY Co., Shanghai, China). The tubular fragments were subsequently resuspended in $45 \%$ percoll in phosphate-buffered saline (PBS), and centrifuged at 20,000 xg for $10 \mathrm{~min}$. High-density tubular fragments were removed and cultured in serum-free, hormonally defined Dulbecco's modified Eagle's medium (DMEM)/F12 medium (HyClone, GE Healthcare, Little Chalfont, UK) containing penicillin $(50 \mathrm{U} / \mathrm{ml})$ and streptomycin $(50 \mu \mathrm{g} / \mathrm{ml}$; Invitrogen Life Technologies, Carlsbad, CA, USA).

HK-2 cells, a permanent and well-characterized human proximal tubular cell line immortalized by transduction with human papillomavirus 16 E6/E7 genes, were purchased from the China Center for Type Culture Collection (Wuhan, China). HK-2 cells were cultured in DMEM/F12 supplemented with $10 \%$ fetal bovine serum (FBS; Gibco-BRL, Invitrogen Life Technologies), $50 \mathrm{U} / \mathrm{ml}$ penicillin and $50 \mu \mathrm{g} / \mathrm{ml}$ streptomycin. Serum-free medium was used when serum starvation was required.

Reverse transcription quantitative polymerase chain reaction $(R T-q P C R)$. Total RNA extraction was performed using TRIzol ${ }^{\circledR}$ reagent (Invitrogen Life Technologies). cDNA synthesis (2 $\mu \mathrm{g}$ total RNA) was performed using Omniscript Reverse Transcriptase (Qiagen, Hilden, Germany) for first-strand cDNA synthesis and oligo-deoxythymine primer generation according to the manufacturer's instructions. The mRNA expression levels of BMP2, OPN, VDR and housekeeping gene $\beta$-actin were analyzed using qPCR on a Rotor Gene 3000 (Corbett Research, Sydney, Australia) using SYBR Premix Ex TaqII (Takara Bio, Inc., Otsu, Japan). Amplification reactions were performed under the following conditions: $95^{\circ} \mathrm{C}$ denaturation for $10 \mathrm{~min}$, followed by 40 cycles of $95^{\circ} \mathrm{C}$ for $15 \mathrm{sec}, 59^{\circ} \mathrm{C}$ for $15 \mathrm{sec}$ and $72^{\circ} \mathrm{C}$ for $30 \mathrm{sec}$. The primer sequences used were as follows: BMP2 forward, 5'-CTTCTAGCGTTGCTGCTTCC-3' and reverse, 5'-AGAGCCTGCGATACAGGTCT-3'; OPN forward, 5'-GCCAAACGCCGACCAAGGTACA-3' and reverse, 5'-TTCCTGCACAGTCACCCACTGAA-3'; VDR forward, 5'-GCCCACCATAAGACCTACGA-3' and reverse, 5'-AGATTGGAGAAGCTGGACGA-3'; $\beta$-actin forward, 5'-CACGATGGAGGGGCCGGACTCATC-3' and reverse, 5'-TAAAGACCTCTATGCCAACACAGT-3'. The Ct values were calculated using the comparative $\mathrm{Ct}(\Delta \Delta \mathrm{Ct})$ method. The fold difference was calculated using the $2^{-\Delta \Delta C t}$ method.

Western blot analysis. Extracts of total cellular proteins were prepared by scraping the cells into Mammalian Protein 
Extraction reagent (78503; Pierce, Thermo Fisher Scientific Inc., Rockford, IL, USA). Protein concentration was detected using the bicinchoninic acid (BCA) protein assay kits (\#23235; Pierce). The protein samples were separated by $12 \%$ SDS-PAGE and electrotransferred onto polyvinylidene difluoride-nitrocellulose membranes (Immobilon-P; EMD Millipore, Billerica, MA, USA). Blots were incubated with mouse monoclonal immunoglobulin (Ig)G ${ }_{2 \mathrm{a}}$ BMP2 antibody (SC-137087; 1:200; Santa Cruz Biotechnology Inc., Dallas, TX, USA), polyclonal rabbit anti-human IgG OPN antibody (BA1678; 1:400; Boster Systems, Inc., Pleasanton, CA, USA) or polyclonal rabbit anti-human IgG VDR antibody (BA2877-2; 1:400; Boster Systems, Inc.). In addition, polyclonal rabbit anti-GAPDH IgG antibody (2275-PC-100; 1:1,000; R\&D Systems, Inc.) was usedto ensure equal loading. The membranes were incubated with secondary antibodies (goat anti-human IgG-horseradish peroxidase; 1:2,000; Pierce). Proteins were detected using enhanced chemiluminescence (ECL) Prime western blotting detection reagent (GE Healthcare). The blots were quantified by densitometry using TotalLab Quant software (TL120 v2009; TotalLab Ltd, Newcastle upon Tyne, UK).

Treatment of TGF- $\beta 1$ and $\mathrm{Ca}^{2+}$ for PRECs and HK-2. PRECs and HK-2 cells were cultured and passaged to the third generation prior to treatment with TGF- $\beta 1$ (PeproTech Inc., Rocky Hill, NJ, USA) and/or $\mathrm{Ca}^{2+}$ in the form of calcium chloride (Fortuna Chemical Co., Wuhan, China) at different concentrations. To inhibit translation, cycloheximide $(5 \mu \mathrm{g} / \mathrm{ml}$, Sigma-Aldrich, St. Louis, MO, USA) was added $30 \mathrm{~min}$ prior to the addition of TGF- $\beta 1$ for the indicated time-period. The concentrations of TGF- $\beta 1$ were $0.5,2.0$ and $5.0 \mathrm{ng} / \mathrm{ml}$, while the $\mathrm{Ca}^{2+}$ concentrations were $0.5,1.5$ and $2.5 \mathrm{mM}$. All cells were plated in 24-well plates at $4 \times 10^{9}$ cells/well in DMEM supplemented with $10 \%$ FBS for 24 h prior to experiments.

Statistical analysis. Differences among groups were assessed using one-way analysis of variance combined with the Bonferroni test using SPSS 13.0 (SPSS Inc., Chicago, IL, USA). Student's t-test was used to compare two independent samples. Values are expressed as the mean \pm standard deviation. $\mathrm{P}<0.05$ was considered to indicate a statistically significant difference between values.

\section{Results}

Serum TGF- $\beta 1, B M P 2$ and $O P N$ concentrations are significantly higher in patients with IH than those in age-matched controls. Serum samples from a total of 58 patients from the $\mathrm{IH}$ and $\mathrm{nIH}$ groups, and 29 subjects from the NC group were analyzed by ELISA to detect serum TGF- $\beta 1$, BMP2 and OPN levels. As shown in Fig. 1, TGF- $\beta 1$, BMP2 and OPN serum levels were all significantly higher in $\mathrm{IH}$ patients than those in the NC group $(\mathrm{P}<0.01)$. The higher expression levels of TGF- $\beta$ (Fig. 1A) and OPN (Fig. 1B) in the nIH group compared with those in the $\mathrm{NC}$ group $(\mathrm{P}<0.01)$ suggested that these factors were significantly increased in patients with renal stones. Furthermore, the results also indicated that the expression levels of all three cytokines in the IH group were significantly higher than those in the $\mathrm{nIH}$ group $(\mathrm{P}<0.01)$, suggesting that $\mathrm{Ca}^{2+}$ may be a critical factor in regulating cytokine secretion.
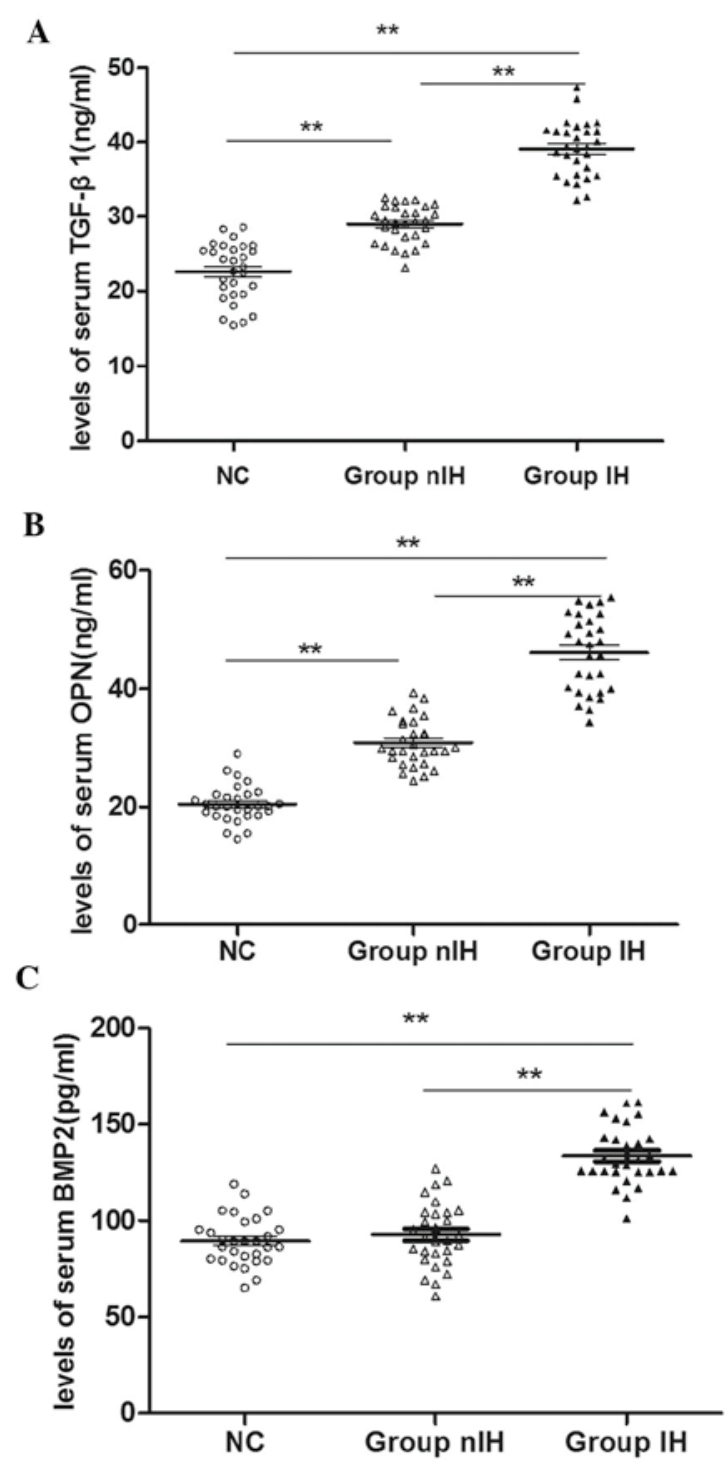

Figure 1. Serum expression levels of TGF- $\beta 1$, BMP2 and OPN in the IH, nIH and NC groups. Expression levels were determined by ELISA. (A) TGF- $\beta 1$ expression levels in the IH group were significantly higher than those in the $\mathrm{NC}$ group. Expression levels of TGF- $\beta 1$ in the $\mathrm{nIH}$ group were also significantly higher than those in the NC group. Serum TGF- $\beta 1$ expression was also significantly different between the $\mathrm{nIH}$ and NC groups. (B) Significant differences were also detected in the serum expression levels of OPN between each group. (C) VDR expression levels in the IH group were significantly higher than those in the NC group and levels of VDR in the IH group were significantly higher than those in the nIH group. There were no significant differences in serum VDR expression levels between the $\mathrm{nIH}$ and $\mathrm{NC}$ groups. Values are expressed as the mean \pm standard deviation $(\mathrm{n}=29)$. ${ }^{* *} \mathrm{P}<0.01$. TGF- $\beta 1$, transforming growth factor- $\beta 1$; BMP 2 , bone morphogenetic protein 2; OPN, osteopontin; VDR, 1,25-dihydroxyvitamin $\mathrm{D}_{3}$ receptor; $\mathrm{IH}$, idiopathic hypercalciuria; group $\mathrm{IH}$, patients with $\mathrm{IH}$; group $\mathrm{nIH}$, renal stone patients without IH; NC, healthy age-matched controls.

Basal expression levels of BMP2 and VDR are higher in PRECs than those in $H K-2$ cells. Basal levels of bone-associated factors BMP2, OPN and VDR were evaluated in PRECs and HK-2 cells. As shown in Fig. 2A, the results of RT-qPCR analysis demonstrated that mRNA expression levels of BMP2, OPN and VDR were significantly higher in PRECs than those in HK-2 cells $(\mathrm{P}<0.05)$. Western blot analysis (Fig. 2B) confirmed that there were analogous variations in BMP2 and VDR protein expression between PRECs and HK-2 cells $(\mathrm{P}<0.05)$. By contrast, no 


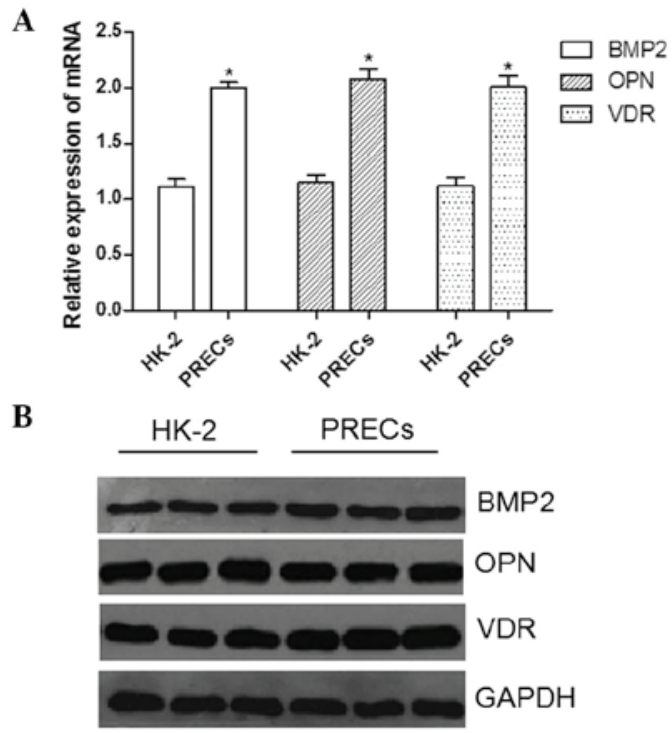

Figure 2. Basal levels of bone-associated factors BMP2, OPN and VDR were detected in PRECs and HK-2 cells. Expression levels were determined by (A) reverse transcription quantitative polymerase chain reaction and (B) western blot analysis. The expression levels of BMP2, OPN and VDR in PERCs were significantly higher than those in HK-2 cells. Expression levels of housekeeping gene GAPDH were determined to ensure equal loading. Values are expressed as the mean \pm standard deviation $(\mathrm{n}=3)$. ${ }^{*} \mathrm{P}<0.05$ vs HK-2 cells. BMP2, bone morphogenetic protein 2; OPN, osteopontin; VDR, 1,25-dihydroxyvitamin $\mathrm{D}_{3}$ receptor; PRECs, primary renal epithelial cells; mRNA, messenger RNA.

significant difference was detected in OPN protein expression levels between the two types of cell $(\mathrm{P}=0.076)$.

Bone-associated factors are significantly increased by TGF- $\beta 1$ or $\mathrm{Ca}^{2+}$ stimulation alone in PRECs compared with those in HK-2 cells. To determine whether TGF- $\beta 1$ or $\mathrm{Ca}^{2+}$ influenced the changes in bone-associated factors in PRECs and HK-2 cells in vitro, the mRNA expression levels of BMP2, OPN and VDR were examined in each group. Cells were cultured with cycloheximide to inhibit further protein synthesis so that only mRNAs of direct TGF- $\beta 1$ targets were activated. Subsequently, various concentrations of TGF- $\beta 1$ $(0.5,2.0$ and $5.0 \mathrm{ng} / \mathrm{ml})$ and calcium chloride $(0.5,1.5$ and $2.5 \mathrm{mM}$ ) were added, and RNA was assessed following $48 \mathrm{~h}$ of incubation. Total mRNA from PRECs treated with TGF- $\beta 1$ and $\mathrm{Ca}^{2+}$, respectively, was compared with mRNA extracted from analogously treated HK-2 cells. As shown in Fig. 3, following incubation with TGF- $\beta 1$, the mRNA expression levels of BMP2, OPN and VDR in PRECs steadily increased in a dose-dependent manner; however, no significant differences were detected in HK- 2 cells with increasing TGF- $\beta 1$ dosage. The levels of BMP2, OPN and VDR in PRECs treated with TGF- $\beta 1$ at doses of $2.0-5.0 \mathrm{ng} / \mathrm{ml}$ were significantly higher than those in PRECs prior to treatment (Fig. 3A-C). Furthermore, the BMP2, OPN and VDR mRNA expression levels induced by treatment with $5.0 \mathrm{ng} / \mathrm{ml} \mathrm{TGF}-\beta 1$ were significantly higher than those induced by $2.0 \mathrm{ng} / \mathrm{ml} \mathrm{TGF}-\beta 1$ $(\mathrm{P}<0.05)$. Analogously with these trends, when the dose of $\mathrm{Ca}^{2+}$ was increased from 0.5 to $2.5 \mathrm{mM}$, the gene expression levels of bone-associated factors in PRECs increased. In particular, a statistically significant increase in expression levels was observed following treatment with $2.5 \mathrm{mM} \mathrm{Ca}^{2+}$, compared to those in untreated PRECs $(\mathrm{P}<0.01$; Fig. 3). The results also indicated that the fold change in VDR mRNA expression levels in PRECs induced by $\mathrm{Ca}^{2+}$ treatment at concentrations of 1.5 and $2.5 \mathrm{mM}$ were significantly different (Fig. 3F). These data indicated that the primary isolated cells from patients with $\mathrm{IH}$ exhibited a consistent and dose-dependent response to TGF- $\beta 1$ and $\mathrm{Ca}^{2+}$ alone, via the activation of bone-associated genes.

Combined stimulation with TGF- $\beta 1$ and $\mathrm{Ca}^{2+}$ significantly increases cellular bone-associated factor expression in PRECs and $H K-2$ cells. The effects of treatment with a combination of TGF- $\beta 1(5.0 \mathrm{ng} / \mathrm{ml})$ and $\mathrm{Ca}^{2+}(2.5 \mathrm{mM})\left(\mathrm{TGF}-\beta 1+\mathrm{Ca}^{2+}\right)$ were evaluated in order to elucidate whether this induced the upregulation of cellular bone-associated factors in HK-2 cells and PRECs. A previous study revealed that in renal epithelial cell culture, TGF- $\beta 1$ activated a program of mesenchymal marker gene expression associated with the transition of epithelial cells to more mesenchymal phenotypes (5). In the present study, it was therefore hypothesized that $\mathrm{Ca}^{2+}$ may have a significant role in enhancing TGF- $\beta$-induced EMT. As shown in Fig. 4, the mRNA expression levels of BMP2, OPN and VDR in HK-2 cells and PRECs which were treated with TGF- $\beta 1+\mathrm{Ca}^{2+}$ were significantly higher than those of the control group $(\mathrm{P}<0.01)$. This result suggested that $\mathrm{Ca}^{2+}$ may have a synergistic effect on the mechanism of TGF- $\beta$-induced EMT, and promote cells expressing mesenchymal markers to differentiate into cells with bone-associated phenotypes. The results displayed in Fig. 4A confirmed that there were no significant differences in BMP2 mRNA expression fold-change between $\mathrm{HK}-2$ cells and PRECs following TGF- $\beta 1+\mathrm{Ca}^{2+}$ treatment $(\mathrm{P}>0.05)$. It was also demonstrated that there were no significant differences in the mRNA expression levels of OPN between HK-2 cells and PRECs following TGF- $\beta 1+\mathrm{Ca}^{2+}$ treatment $(\mathrm{P}>0.05)$. By contrast, significant differences between HK-2 cells and PRECs were detected in the expression of VDR mRNA following TGF- $\beta 1+\mathrm{Ca}^{2+}$ treatment $(\mathrm{P}<0.05$; Fig. 4C).

BMP2 mRNA levels increase in a time-dependent manner in response to TGF- $\beta 1$ and $\mathrm{Ca}^{2+}$ stimulation in $\mathrm{HK}-2$ cells and PRECs. In HK-2 cells, examination of BMP2 mRNA expression levels following treatment with TGF- $\beta 1$ and $\mathrm{Ca}^{2+}$ by RT-qPCR analysis suggested that levels began to increase at $12 \mathrm{~h}$ following co-culture and continued to increase up until 48 h. At 48 h, BMP2 mRNA expression levels were significantly higher than those induced by TGF- $\beta 1$ or $\mathrm{Ca}^{2+}$ stimulation alone $(\mathrm{P}<0.01)$. Of note, an analogous trend was observed in PRECs following incubation with TGF- $\beta 1+\mathrm{Ca}^{2+}$ (Fig. 5B). Furthermore, the results demonstrated that BMP2 mRNA levels stimulated by TGF- $\beta 1+\mathrm{Ca}^{2+}$ treatment were significantly increased compared with those in PRECs treated with TGF- $\beta 1(\mathrm{P}<0.05)$ or $\mathrm{Ca}^{2+}$ $(\mathrm{P}<0.01)$ alone at $48 \mathrm{~h}$. Furthermore, a significant difference was observed in BMP2 expression levels in PRECs induced by treatment with TGF- $\beta 1$ and $\mathrm{Ca}^{2+}$ alone $(\mathrm{P}<0.05)$.

\section{Discussion}

The results of the present study indicated that TGF- $\beta 1$ and $\mathrm{Ca}^{2+}$ had a synergistic effect on the differentiation of PRECs 

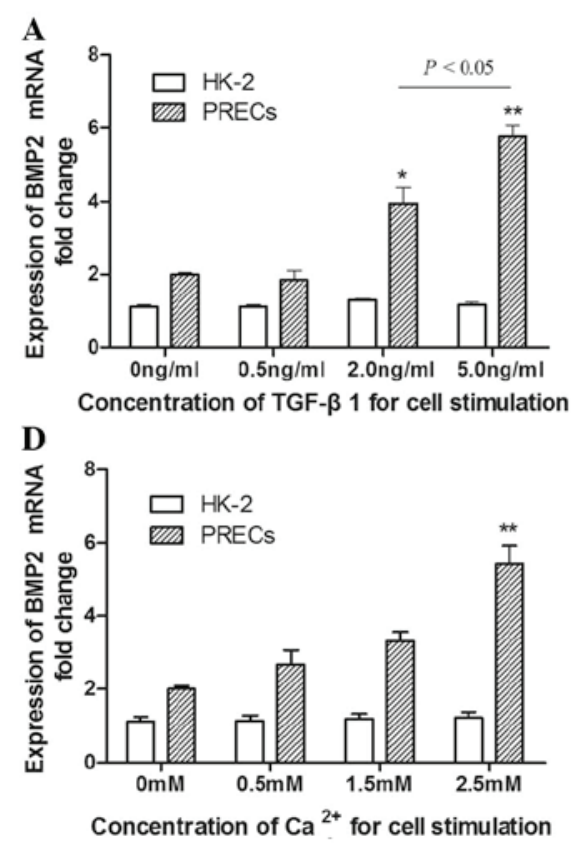
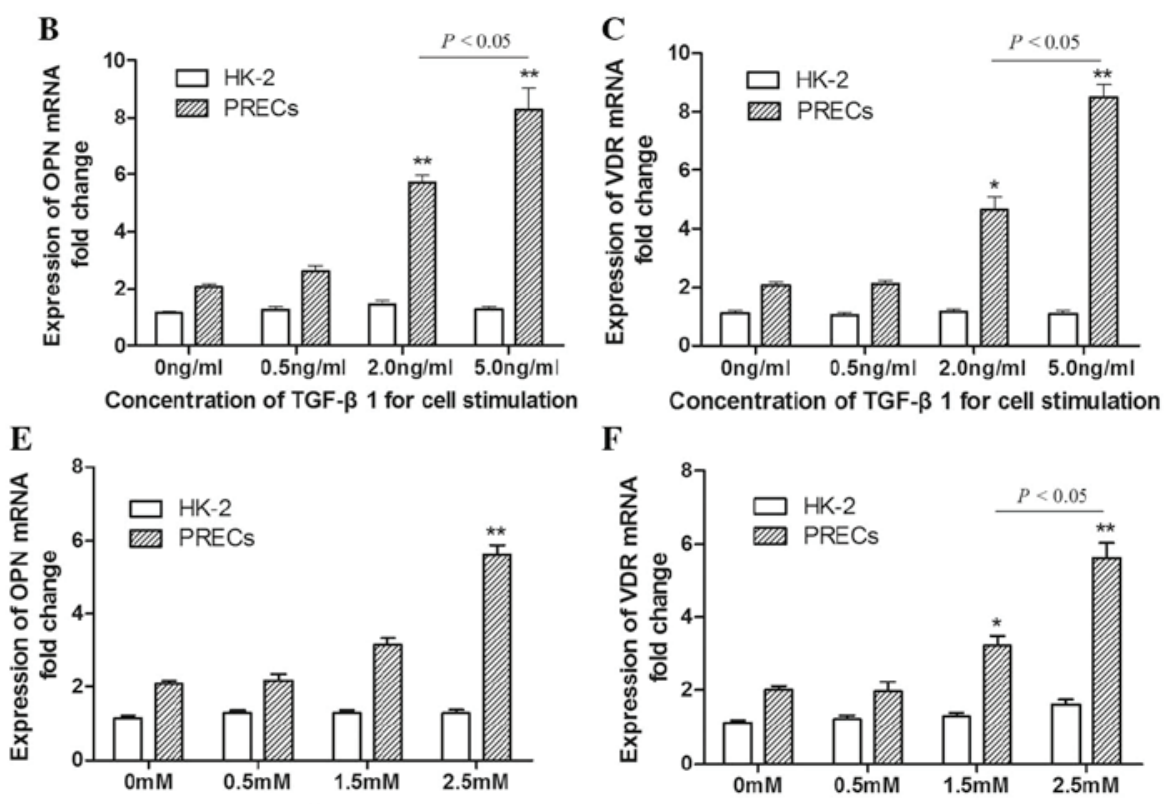

Concentration of $\mathrm{Ca}^{2+}$ for cell stimulation
F

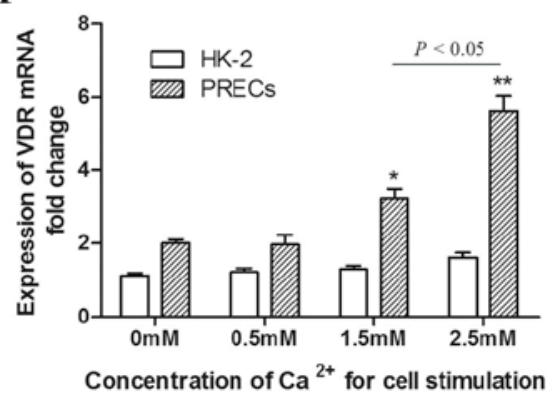

Figure 3. Bone-associated factors were detected using reverse transcription quantitative polymerase chain reaction in PRECs and HK-2 cell lines following incubation with TGF- $\beta 1$ or $\mathrm{Ca}^{2+}$ alone for $48 \mathrm{~h}$. (A) mRNA expression levels of BMP2 in PRECs increased in a dose-dependent manner following incubation with TGF- $\beta 1$ at various concentrations. BMP2 mRNA expression levels were significantly higher following incubation with TGF- $\beta 1$ at 2.0 and $5.0 \mathrm{ng} / \mathrm{ml}$ than those prior to treatment. No significant differences were detected in HK-2 cells following identical treatment with TGF- $\beta 1$. (B) OPN and (C) VDR mRNA expression levels in PRECs treated with TGF- $\beta 1$ also increased in a dose-dependent manner. OPN and VDR expression levels were statistically different at concentrations of 2.0 and $5.0 \mathrm{ng} / \mathrm{ml}$ compared with those in PRECs prior to treatment. (D) When the dose of Ca ${ }^{2+}$ was increased from 0.5 to $2.5 \mathrm{mM}$, the gene expression profile of BMP2 increased, and this increase was statistically significant at $2.5 \mathrm{mM}$. An analagous effect was observed in the expression profiles of (E) OPN and (F) VDR. Furthermore, the increase in VDR mRNA expression caused by $\mathrm{Ca}^{2+}$ treatment at $2.5 \mathrm{mM}$ was significantly greater than that at $1.5 \mathrm{mM}$. Values are expressed as the mean \pm standard deviation. ${ }^{*} \mathrm{P}<0.05,{ }^{* *} \mathrm{P}<0.01$ vs. untreated cells. TGF- $\beta 1$, transforming growth factor- $\beta 1$; BMP2, bone morphogenetic protein 2 ; OPN, osteopontin; VDR, 1,25 -dihydroxyvitamin $\mathrm{D}_{3}$ receptor; PRECs, primary renal epithelial cells; mRNA, messenger RNA.

A

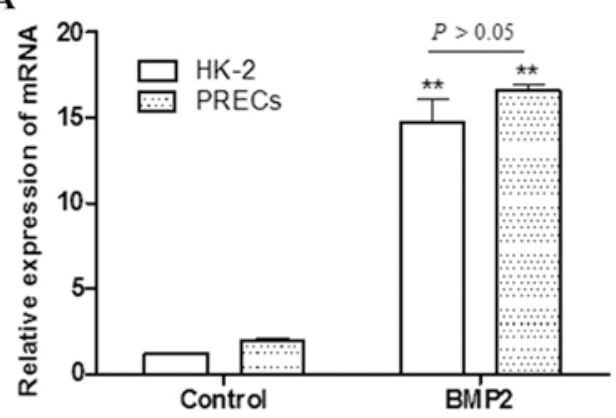

C

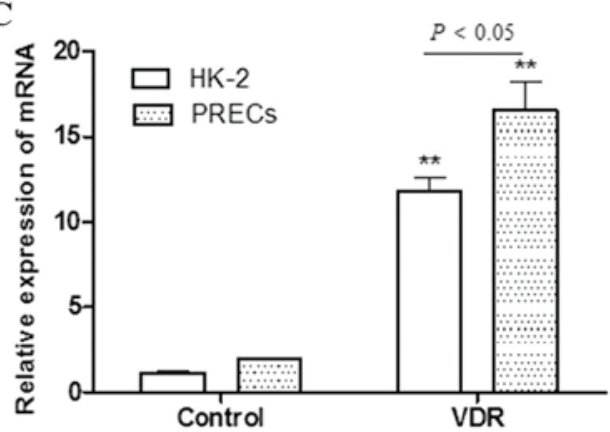

B

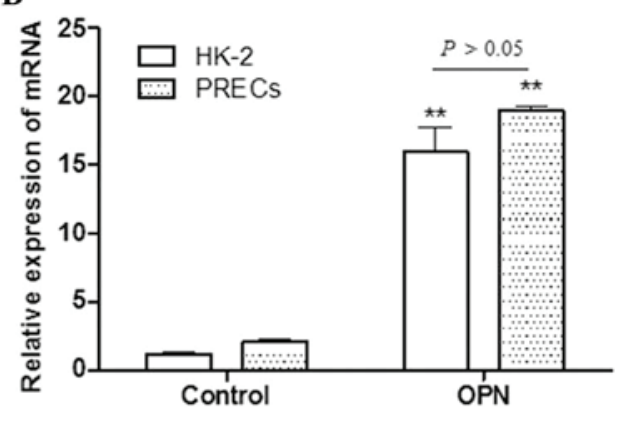

D

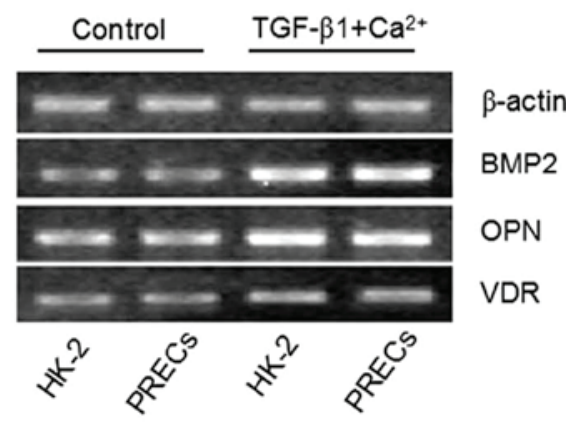

Figure 4. Effects of combined stimulation with TGF- $\beta 1$ and $\mathrm{Ca}^{2+}$ on bone-associated factor expression in HK-2 cells and PRECs. mRNA expression levels of (A) BMP2, (B) OPN and (C) VDR in HK-2 and PRECs following incubation with TGF- $\beta 1(5.0 \mathrm{ng} / \mathrm{ml})$ and $\mathrm{Ca}^{2+}(2.5 \mathrm{mM})$, in combination, were significantly higher than those in the control group. VDR mRNA expression levels following co-incubation with TGF- $\beta 1$ and $\mathrm{Ca}^{2+}$ were significantly different between HK-2 cells and PRECs. Values are expressed as the mean \pm standard deviation. ${ }^{* *} \mathrm{P}<0.01$ vs. control group. (D) Representative gel from three independent experiments. TGF- $\beta 1$, transforming growth factor- $\beta 1$; BMP2, bone morphogenetic protein 2 ; OPN, osteopontin; VDR, 1,25 -dihydroxyvitamin $\mathrm{D}_{3}$ receptor; PRECs, primary renal epithelial cells; mRNA, messenger RNA. 

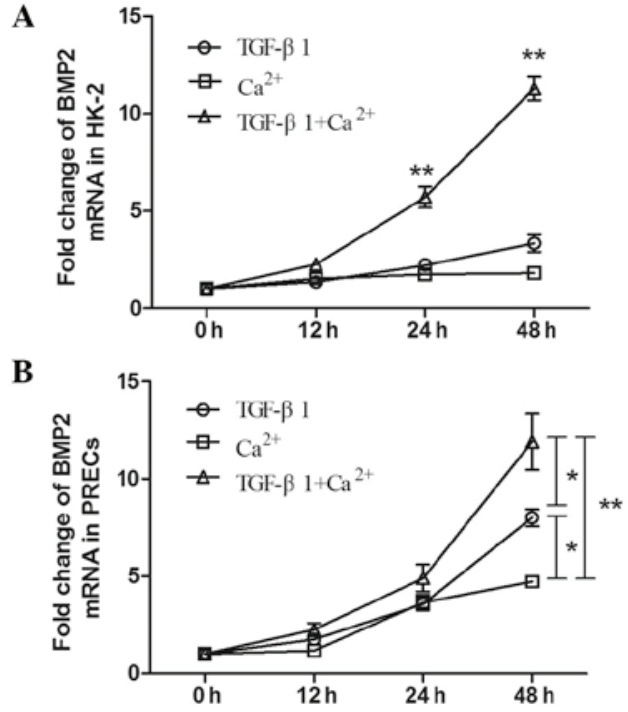

Figure 5. Time-dependent fold-change in BMP2 mRNA expression levels in HK-2 cells and PRECs following TGF- $\beta 1$ and/or $\mathrm{Ca}^{2+}$ stimulation. (A) Following co-culture with TGF- $\beta 1(5.0 \mathrm{ng} / \mathrm{ml})$ and $\mathrm{Ca}^{2+}(2.5 \mathrm{mM})$, BMP2 mRNA expression levels in HK-2 cells increased in a time-dependent manner and were significantly higher than those following TGF- $\beta 1$ or $\mathrm{Ca}^{2+}$ stimulation alone at 24 and $48 \mathrm{~h}\left({ }^{* *} \mathrm{P}<0.01\right)$. (B) A similar trend was observed in PRECs following incubation with TGF- $\beta 1+\mathrm{Ca}^{2+}$. In addition, levels of BMP2 stimulated by TGF- $\beta 1+\mathrm{Ca}^{2+}$ were significantly increased compared with those following TGF- $\beta 1(\mathrm{P}<0.05)$ or $\mathrm{Ca}^{2+}(\mathrm{P}<0.01)$ stimulation alone at $48 \mathrm{~h}$. A significant difference was also observed between expression levels induced by treatment with TGF- $\beta 1$ and $\mathrm{Ca}^{2+}$ alone $\left({ }^{*} \mathrm{P}<0.05\right)$. Values are expressed as the mean \pm standard deviation.TGF- $\beta 1$, transforming growth factor- $\beta 1$; BMP2, bone morphogenetic protein 2 ; primary renal epithelial cells; mRNA, messenger RNA.

and HK-2 cell lines, and regulated the mRNA and protein expression levels of bone- and nephrolithiasis-associated factors BMP2, OPN and VDR. In addition, expression levels of these factors were significantly increased following stimulation with TGF- $\beta 1$ and $\mathrm{Ca}^{2+}$ alone in PRECs, but not in HK-2 cells. Furthermore, serum TGF- $\beta 1$, BMP 2 and OPN levels were significantly upregulated in patients with renal stones compared with those in healthy controls. The mechanism underlying these changes may be associated with TGF- $\beta$-induced EMT and $\mathrm{Ca}^{2+}$-linked ion channel activation for differentiation of renal epithelial cells. It was therefore hypothesized that this process may be a vital physiological and pathological mechanism underlying renal stone formation in $\mathrm{IH}$.

TGF- $\beta$ s are multifunctional growth factors which participate in numerous pathophysiological processes, including cell differentiation, proliferation, embryonic development, wound healing, extracellular matrix (ECM) formation, development of the immune and nervous systems, conferment of immunity and tumorigenesis (11-13). Amongst mammals, the most abundant form of TGF- $\beta$ is TGF- $\beta 1$, which is synthesized by multiple cells, including all types of kidney cell, and is secreted as a latent precursor complexed with TGF- $\beta$-binding proteins (14). Stimulation of TGF- $\beta$ receptors in the cell membrane induces the activation of intracellular signaling pathways, which modulate numerous developmental, physiological and pathological processes, including renal fibrosis and podocyte injury, which influence renal glomerular filtration barrier function. The TGF- $\beta$ membrane receptor complex is made up of proteins from two families which have serine/threonine kinase activity: Type II (T $\beta R I I)$ (13) and type I (T $\beta R I)$ receptors, which include activin-like kinase receptors. TGF- $\beta$ binds to T $\beta$ RII, which recruits T $\beta R I$ to form a receptor complex, which is subsequently phosphorylated and activates multiple intracellular signaling cascades, including Smad2/3. Smad2/3 heterotrimerizes with co-activator Smad4, resulting in nuclear translocation of the complex, which subsequently induces the transcription of TGF- $\beta$-responsive genes via the activation of Smad-binding elements on their promoters (15). TGF- $\beta 1$ additionally recruits non-Smad pathways in order to activate mitogen-activated protein kinases, including Wnt/ $\beta$-catenin. These effectors modulate the expression of specific target genes, which may be involved in physiological or kidney disease-associated events, including cellular growth, differentiation, apoptosis, ECM deposition and EMT (16). Previous studies have also revealed that TGF- $\beta 1$ is a pivotal signaling molecule in the Wnt pathway. Of note, the canonical Wnt/ $\beta$-catenin signaling pathway was found to be involved in mediating the EMT and TGF- $\beta 1$-mediated fibrosis (17-19). Activation of canonical Wnt signaling with a Wnt ligand was found to be triggered by TGF- $\beta 1$-induced upregulation of mesenchymal marker genes, including Zeb1, Snail1 and $\alpha$ SMA, in renal epithelial cells, whereas inhibition of the TGF- $\beta 1$ pathway alleviated the severity of progressive renal fibrosis and EMT (20). This effect was also investigated in asthmatic bronchial epithelial cells, which were induced by treatment with a combination of interleukin-22 and TGF- $\beta 1$ (21). A previous study also revealed that Wnt signaling prevented proteolytic processing of $\beta$-catenin by the proteasome, resulting in $\beta$-catenin accumulation in the cytoplasm and interaction with T-cell factor/lymphoid enhancer-binding factor proteins to regulate gene and protein expression (22). Furthermore, Hill et al (23) observed that the BMP and Wnt signaling pathways tightly regulate each other. Activation of the Wnt signaling pathway induces the expression of members of the BMP family, including BMP2, BMP4, and BMP7, as well as increasing the expression of BMP target genes, for example Msh homeobox 2 (Msx2) and gremlin, in the mesenchyme, a process which also occurs during osteoblast differentiation and bone formation (24). In brief, downstream genes were activated by TGF- $\beta 1$ via the Wnt signaling pathway. At present, the BMP2 signaling pathway is known to include BMP2, Runt-related transcription factor 2 (Runx2), Msx and Osterix. BMP2, which belongs to the TGF- $\beta$ superfamily, is a critical mediator of osteogenesis physiology, due to its ability to upregulate Msx2 and Runx2, which are key regulators of osteoblastic differentiation (25). A previous study by our group indicated that the upregulation of 1,25-dihydroxyvitamin $\mathrm{D}_{3}$ induced an increase in the expression of BMP2, Runx2 and Osterix in PRECs (26). In addition, it was also found that bone-associated factors, including BMP2, Runx2, Osterix and OPN, had an important role in renal stone formation in IH (data not shown). Furthermore, VDR knockdown reduced the expression levels of BMP2, Runx2, Osterix and OPN, as well as decreasing the tubular calcium phosphate deposits in the genetic hypercalciuric rat model of IH (26). It was therefore postulated that TGF- $\beta 1$ was a crucial factor in 
urolithiasis formation in patients with $\mathrm{IH}$, and that upregulation of TGF- $\beta 1$ may increase the expression of markers of osteoblastic cells in PRECs and renal tissue from patients with IH. The results of the present study indicated that the mRNA expression levels of BMP2, OPN and VDR in PRECs increased in a dose-dependent manner following incubation with TGF- $\beta 1$. The expression levels of BMP2, OPN and VDR in PRECs, which were treated with TGF- $\beta$ at doses of 2.0-5.0 ng/ml, were significantly higher than those in PRECs prior to treatment. It was also demonstrated that TGF- $\beta$ expression levels were significantly higher in patients with $\mathrm{IH}$ than those in the $\mathrm{NC}$ and $\mathrm{nIH}$ groups. These results confirmed our prior hypothesis stating the essentiality of TGF- $\beta$-induced differentiation of renal epithelial cells in urolithiasis formation.

Hypercalciuria is the most common abnormality identified amongst calcium stone formers (27). However, the role of hypercalciuria in stone formation remains to be elucidated. High urinary calcium concentrations lead to increased saturation of urinary calcium salts and inhibitory activity via complexion with negatively charged inhibitors, including citrate and chondroitin sulfate (4). The intracellular concentration of calcium has been shown to be an important regulator of gene expression patterns during numerous cellular physiological development processes (28). An association between extracellular calcium stimulation and vascular calcification has emerged and studies have revealed that increasing calcium concentration to levels observed in hypercalcemic individuals increased the mineralization of human smooth muscle cell cultures at normal phosphorus levels $(29,30)$. Furthermore, examination of calcified vessels in humans and animals revealed the expression of BMP2, OPN, VDR and osteoblast transcription factors, including Runx $2 / \mathrm{Cbfa} 1$, Osterix and Msx2, which suggested that calcium has an essential role in ectopic calcification (25). The effects of calcium on cells may be mediated through multiple receptors. Chang et al (31) investigated the hypothesis that extracellular calcium may enhance terminal differentiation and mineralization of osteoblast precursor cells via a calcium receptor-sensitive mechanism. Similarly, L-type calcium channels have been implicated in the calcium-mediated regulation of osteoblastic differentiation (24). In the present study, levels of BMP2, OPN, VDR in PRECs of the IH group were found to exhibit a consistent and dose-dependent response to $\mathrm{Ca}^{2+}$ stimulation alone. These results suggested that $\mathrm{Ca}^{2+}$ may be closely associated with ectopic calcification in calcium stone formation in patients with $\mathrm{IH}$, and it was concluded that $\mathrm{Ca}^{2+}$ may promote the cellular differentiation of PRECs and enhance TGF- $\beta$-induced EMT. However, the mechanisms underlying the cross-talk between TGF- $\beta 1$ and calcium in PRECs in the nephron remain to be elucidated.

In conclusion, the present study demonstrated that TGF- $\beta 1$ regulated the expression of BMP2, OPN and VDR in PRECs, but not in HK-2 cells. Furthermore, co-incubation with TGF- $\beta 1$ and $\mathrm{Ca}^{2+}$ significantly increased the expression levels of bone-associated factors in PRECs and HK-2 cells. Further studies are required in order to elucidate the specific mechanism underlying the association between $\mathrm{Ca}^{2+}$-stimulated and TGF- $\beta 1$-induced EMT and the process of cell differentiation in hypercalciuria. Furthermore, the present study supplied experimental evidence that the pathogenesis of calcium stone development is associated with bone formation.

\section{Acknowledgements}

The present study was funded by grants from the National Natural Science Foundation of China (nos. 30972985 and 81270787).

\section{References}

1. Worcester EM and Coe FL: Nephrolithiasis. Prim Care 35: 369-391, 2008

2. van't Hoff WG: Aetiological factors in paediatric urolithiasis. Nephron Clin Pract 98: c45-c48, 2004.

3. Worcester EM, Bergsland KJ, Gillen DL, et al: Evidence for increased renal tubule and parathyroid gland sensitivity to serum calcium in human idiopathic hypercalciuria. Am J Physiol Renal Physiol 305: F853-F860, 2013.

4. Yoon V, Adams-Huet B, Sakhaee K and Maalouf NM: Hyperinsulinemia and urinary calcium excretion in calcium stone formers with idiopathic hypercalciuria. J Clin Endocrinol Metab 98: 2589-2594, 2013.

5. Joan Massagué: TGF $\beta$ in cancer. Cell 134: 215-230, 2008.

6. Böttinger EP and Bitzer M: TGF-beta signaling in renal disease. J Am Soc Nephrol 13: 2600-2610, 2002.

7. Zeisberg EM, Tarnavski O, Zeisberg M, et al: Endothelial to mesenchymal transition contributes to cardiac fibrosis. Nat Med 13: 952-961, 2007.

8. Kawano S, Shoji S, Ichinose S, et al: Characterization of $\mathrm{Ca}(2+)$ signaling pathways in human mesenchymal stem cells. Cell Calcium 32: 165-174, 2002.

9. Coe FL, Parks JH and Asplin JR: The pathogenesis and treatment of kidney stones. N Engl J Med 327: 1141-1152, 1992.

10. Van der Hauwaert C, Savary G, Gnemmi V, et al: Isolation and characterization of a primary proximal tubular epithelial cell model from human kidney by CD10/CD13 double labeling. PLoS One 14: e66750, 2013.

11. Xu L, Kitani A and Strober W: Molecular mechanisms regulating TGF-beta-induced Foxp3 expression. Mucosal Immunol 3: 230-238, 2010.

12. Yang L, Pang Y and Moses HL: TGF-beta and immune cells: an important regulatory axis in the tumor microenvironment and progression. Trends Immunol 31: 220-227, 2010.

13. Meng XM, Huang XR, Xiao J, et al: Diverse roles of TGF- $\beta$ receptor II in renal fibrosis and inflammation in vivo and in vitro. J Pathol 227: 175-188, 2012.

14. Wheeler JB, Ikonomidis JS and Jones JA: Connective tissue disorders and cardiovascular complications: the indomitable role of transforming growth factor-beta signaling. Adv Exp Med Biol 802: 107-127, 2014.

15. Briones-Orta MA, Tecalco-Cruz AC, Sosa-Garrocho M, et al: Inhibitory Smad7: emerging roles in health and disease. Curr Mol Pharmacol 4: 141-153, 2011.

16. Aristidis Moustakas and Paraskevi Heldin: TGF $\beta$ and matrix-regulated epithelial to mesenchymal transition. Biochim Biophys Acta 1840: 2621-2634, 2014.

17. He W, Dai C, Li Y, et al: Wnt/beta-catenin signaling promotes renal interstitial fibrosis. J Am Soc Nephrol 20: 765-776, 2009.

18. Zhou B, Liu Y, Kahn M, et al: Interactions between $\beta$-catenin and transforming growth factor- $\beta$ signaling pathways mediate epithelial-mesenchymal transition and are dependent on the transcriptional co-activator cAMP-response element-binding protein (CREB)-binding protein (CBP). J Biol Chem 287: 7026-7038, 2012.

19. Akhmetshina A, Palumbo K, Dees C, et al: Activation of canonical Wnt signaling is required for TGF- $\beta$-mediated fibrosis. Nat Commun 3: 735, 2012.

20. Ledbetter S, Kurtzberg L, Doyle S, et al: Renal fibrosis in mice treated with human recombinant transforming growth factor-beta2. Kidney Int 58: 2367-2376, 2000.

21. Johnson JR, Nishioka M, Chakir J, et al: IL-22 contributes to TGF- $\beta 1$-mediated epithelial-mesenchymal transition in asthmatic bronchial epithelial cells. Respir Res 14: 118, 2013. 
22. MacDonald, BT, Tamai $\mathrm{K}$ and He X: Wnt/ $\beta$-catenin signaling. Components, mechanisms, and diseases. Dev Cell 17: 9-26, 2009.

23. Hill TP, Taketo MM, Birchmeier W and Hartmann C: Multiple roles of mesenchymal beta-catenin during murine limb patterning. Development 133: 1219-1229, 2006.

24. Zhang RR, Oyajobi BO, Harris SE, et al: Wnt/ $\beta$-catenin signaling activates bone morphogenetic protein 2 expression in osteoblasts. Bone 52: 145-156, 2013

25. Johnson RC, Leopold JA and Loscalzo J: Vascular calcification: pathobiological mechanisms and clinical implications. Circ Res 99: 1044-1059, 2006.

26. Jia ZH, Wang SG, Tang JH, et al: Does stone formation in genetic hypercalciuric rat kidney tissue share similarities with bone formation? Urology 83: 509.e7-509.e17, 2014.

27. Liern M, Bohorquez M and Vallejo G: Treatment of idiopathic hypercalciuria and its impact on associated diseases. Arch Argent Pediatr 111: 110-114, 2013.
28. González-Vázquez A, Planell JA and Engel E: Extracellular calcium and CaSR drive osteoinduction in mesenchymal stromal cells. Acta Biomater 10: 2824-2833, 2014.

29. Yang H, Curinga G and Giachelli CM: Elevated extracellular calcium levels induce smooth muscle cell matrix mineralization in vitro. Kidney Int 66: 2293-2299, 2004.

30. Collin-Osdoby P: Regulation of vascular calcification by osteoclast regulatory factors RANKL and osteoprotegerin. Circ Res 95: 1046-1057, 2004.

31. Chang W, Tu C, Pratt S, et al: Extracellular $\mathrm{Ca}(2+)$-sensing receptors modulate matrix production and mineralization in chondrogenic RCJ3.1C5.18 cells. Endocrinology 143: 1467-1474, 2002. 